\title{
Knowledge of Nurses Concerning Ventilator-Associated Pneumonia (VAP) Prevention in Mosul Teaching Hospitals
}

\author{
Ahmed Ali Hussein \\ Lecturer, University of Mosul, College of Nursing, Mosul, Iraq
}

\begin{abstract}
Background: Ventilator-Associated Pneumonia (VAP) is one of the popular Intensive Care Units (ICUs) nosocomial infections with a prevalence rate of ten to seventy percent. The frequency of VAP is about twenty percent. Lack of awareness of VAP standards and the low quality of nursing practice can become a barrier to preventing VAP.
\end{abstract}

Objective: The purpose of this study is to assess the knowledge of nurses concerning VAP prevention in Mosul teaching Hospitals.

\begin{abstract}
Material and Method: A descriptive design study was used to assess knowledge and sources of knowledge among nurses about VAP prevention. From Mosul Teaching Hospitals picked 200 respondents working in different intensive care areas (ICU, CCU, NICU, and PICU) as a sample for the current study using the accidental sampling approach. Aquestionnaire developed for nurses have been updated and revised for the purpose of the study. The questionnaire was tested for validity and reliability and passed for use in the present study. Using Microsoft Excel, data coding, entry, cleaning, and analysis were done, and results were presented using standard frequency distribution tables.
\end{abstract}

Results: In relation to Sociodemographic data of the studied sample is shown in Table 1. The average age of nurses was founded $(26.13 \pm 4.25)$ years, and $(62.7 \%)$ had a diploma in nursing (secondary schools). Also, the mean experience period was $(7.31 \pm 3.81)$ years. The study found that $(67 \%)$ of Nurses had poor knowledge about pneumonia and VAP. The highest (86\%) of nurse's little knowledge was gained through their practice of nursing in Mosul hospital.

Conclusion: Multieducational and training courses and programs need for nurses to improve their knowledge about prevention of VAP and may decrease Pneumonia associated with Ventilator among patients were concluded in current study.

Keywords: Knowledge, Ventilator, Pneumonia, (VAP).

\section{Introduction}

"Ventilator Associated Pneumonia" (VAP) is a nosocomial lung parenchyma infection that occurs more than 48-72 hours after the intubation of a patient and the initiation of mechanical ventilation ${ }^{(1)}$. It is a subtype of Hospital Acquired Pneumonia that occurs in people on mechanical ventilation via an endotracheal or tracheostomy tube for at least 48 hours with 6-20 times higher incidence recorded in these patients ${ }^{(2)}$. Especially in intensive care units (ICUs), where the reality of the diseases, the circumstances of the patient and the type of micro-organisms involved make infections a severe problem $^{(3)}$. Invasive procedures have been the focus of health-associated infection (HAI) epidemiology studies and are known to be common risk factors, such as central venous catheters for bloodstream infections and mechanical ventilation for pneumonia ${ }^{(4-6)}$. Because patients in the Intensive Care Unit (ICU) focus exclusively on the caregivers, the awareness, perceptions, and behaviors implemented by the nurses have a direct impact on patient recovery. Miserably, oral health issues in chronically ill patients are typically overshadowed by other severe needs. There are major effects of chronic illnesses and disorders, leading to 
disabilities and a decreased quality of life. Individuals with the most prevalent oral conditions tend to have the highest oral disease rates, associating poor oral health with adverse health effects such as aspiration pneumonia and cardiovascular disease ${ }^{(7-10)}$.

Aim: The purpose of this study is to identify knowledge of ventilator-associated pneumonia among critical care nurses.

\section{Method}

A descriptive design study was used to assess knowledge and sources of knowledge among nurses about VAP prevention. From Mosul Teaching Hospitals picked 200 respondents working in different intensive care areas (ICU, CCU, NICU, and PICU) as a sample for the study using the accidental sampling approach. The questionnaires developed for nurses have been updated and revised by professors of Community Health Nursing and was tested for validity and reliability and passed for use in the present study. The information about sociodemographic profiles of health care professionals in the ICU like age, number of years of experience and past attendance of training courses on infection control, were gathered directly from them.Questionsto assess the nurse's knowledge about VAP (what is meaning, risk factors, causes, sources, route of transmission, and mission of infection control as well as Knowledge about recommendations suggested by APIC for reducing associated pneumonia in the ventilator) are arranged and addressed to the participants. The correct answer is marked with (1) and the wrong answer is marked (0). Using Microsoft Excel, data coding, entry, cleaning, and analysis were done, and results were presented using standard frequency distribution tables. Simple proportions have been used to define the numerical and categorical details.

\section{Results}

The average age of nurses was reported $(26.13 \pm$ $4.25)$ years, and (62.7 percent) had a nursing certificate (secondary schools). The mean period of experience was also $(7.31 \pm 3.81)$ years. The study showed that Nurses (67 percent) had no knowledge of pneumonia and VAP. The highest ( 86 percent) of the little awareness of nurses was gained by their nursing practice at Mosul hospital. The study found that (67\%) of Nurses had poor knowledge about pneumonia and VAP. The highest $(86 \%)$ of nurse's knowledge was gained through their practice of nursing in Mosul hospital. One of the top barriers to VAP management, having multiple physician groups managing VAP,can lead to poor patient outcomes, particularly due to the increased likelihood of communication errors in multiple providers. (Table 3).

\section{FIGURE (1) : KNOWLEDGE OF NURSES CONCERNING VAP PREVENTION.}

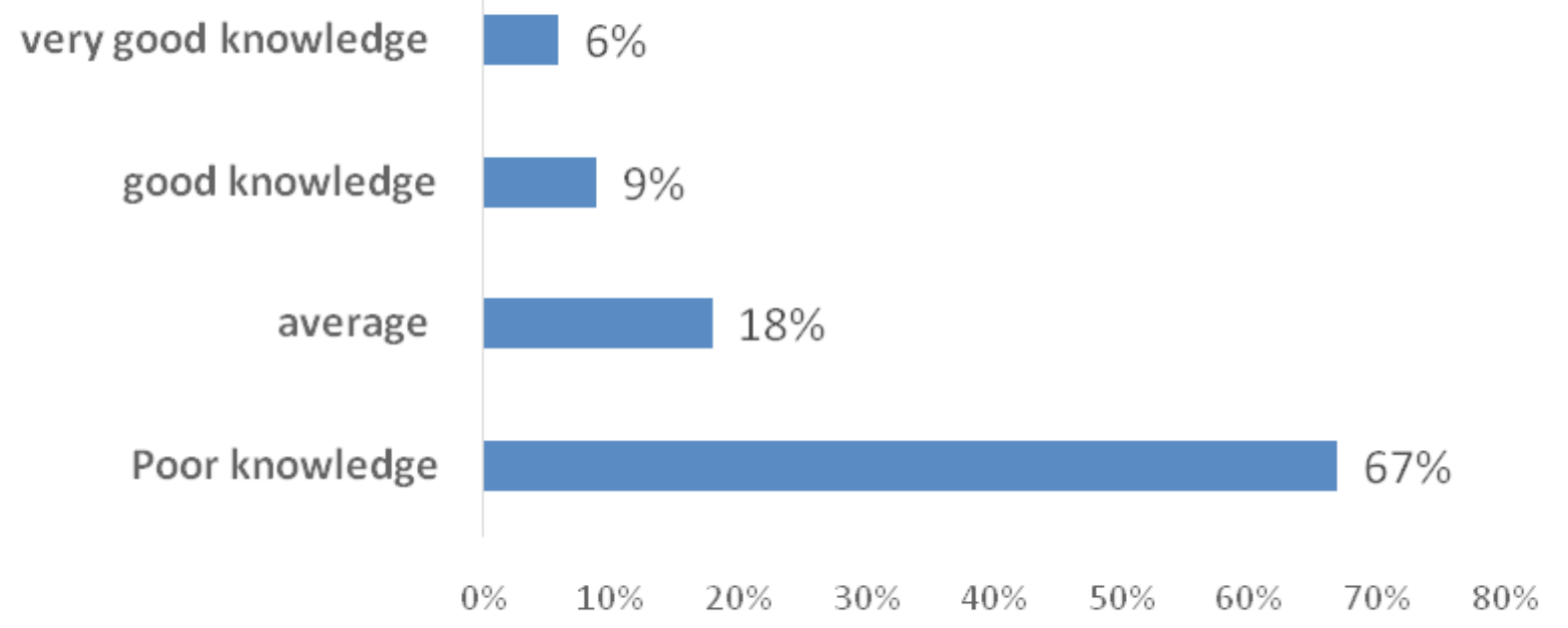


Table (1): Nurses' knowledge about pneumonia in details.

\begin{tabular}{|c|c|c|}
\hline Nurses knowledge about signs and symptoms of pneumonia & $\mathbf{F}$ & $\%$ \\
\hline Poor & 58 & $29 \%$ \\
\hline Average & 48 & $24 \%$ \\
\hline Good \% & 52 & $26 \%$ \\
\hline Very good & 42 & $21 \%$ \\
\hline Total & 200 & $100 \%$ \\
\hline \multicolumn{3}{|l|}{ Chi - Square $=2.72$ P-Value $=0.43$} \\
\hline Nurses knowledge about complications of pneumonia & $\mathbf{F}$ & $\%$ \\
\hline Poor & 122 & $61 \%$ \\
\hline Average & 47 & $23.5 \%$ \\
\hline Good & 31 & $15.5 \%$ \\
\hline Very good & 0 & $0 \%$ \\
\hline Total & 200 & $100 \%$ \\
\hline \multicolumn{3}{|l|}{ Chi - Square $=70.81$ P-Value $=0.00$} \\
\hline Nurses knowledge about causes of pneumonia & $\mathbf{F}$ & $\%$ \\
\hline Poor & 136 & $68 \%$ \\
\hline Average & 32 & $16 \%$ \\
\hline Good & 29 & $14.5 \%$ \\
\hline Very good & 3 & $1.5 \%$ \\
\hline Total & 200 & $100 \%$ \\
\hline \multicolumn{3}{|l|}{ Chi-Square $=207.80$ P-Value $=0.00$} \\
\hline Nurses knowledge about measures of reducing incidence of pneumonia: & $\mathbf{F}$ & $\%$ \\
\hline Poor & 57 & $28.5 \%$ \\
\hline Average & 30 & $15 \%$ \\
\hline Good & 61 & $30.5 \%$ \\
\hline Very good & 52 & $26 \%$ \\
\hline Total & 200 & $100 \%$ \\
\hline \multicolumn{3}{|l|}{ Chi - Square $=11.48$ P-Value $=0.009$} \\
\hline Nurses knowledge about chest X-ray findings: & $\mathbf{F}$ & $\%$ \\
\hline Correct answer & 149 & $74.5 \%$ \\
\hline Incorrect answer & 51 & $25.5 \%$ \\
\hline Total & 200 & $100 \%$ \\
\hline \multicolumn{3}{|l|}{ Chi - Square $=48.02$ P-Value $=0.00$} \\
\hline Nurses knowledge about severity of pneumonia: & $\mathbf{F}$ & $\%$ \\
\hline Correct answer & 58 & $29 \%$ \\
\hline Incorrect answer & 142 & $71 \%$ \\
\hline Total & 200 & $100 \%$ \\
\hline \multicolumn{3}{|l|}{ Chi - Square $=35.28$ P-Value $=0.00$} \\
\hline Nurses knowledge about amount of fluid required for patient with pneumonia: & $\mathbf{F}$ & $\%$ \\
\hline Correct answer & 69 & $34.5 \%$ \\
\hline Incorrect answer & 131 & $65.5 \%$ \\
\hline Total & 200 & $100 \%$ \\
\hline
\end{tabular}


Table (2): Sources of knowledge regarding Pneumonia

\begin{tabular}{|c|c|c|c|c|}
\hline \multirow{2}{*}{ Item } & \multicolumn{2}{|c|}{ Yes } & \multicolumn{2}{|c|}{ No } \\
\hline & $\mathbf{F}$ & $\%$ & $\mathbf{F}$ & $\%$ \\
\hline $\begin{array}{l}\text { Have you received information about pneumonia during your academic study } \\
\text { stage? }\end{array}$ & 184 & $92 \%$ & 16 & $8 \%$ \\
\hline $\begin{array}{l}\text { Did you get information about pneumonia during your practice of nursing in } \\
\text { Mosul hospital? }\end{array}$ & 172 & $86 \%$ & 28 & $14 \%$ \\
\hline Did you search for information in scientific books and the internet? & 80 & $40 \%$ & 120 & $60 \%$ \\
\hline $\begin{array}{l}\text { Have you participated in scientific courses and seminars that deal with the } \\
\text { study of diseases in health institutions and universities? }\end{array}$ & 107 & $53.5 \%$ & 93 & $46.5 \%$ \\
\hline
\end{tabular}

Table (3): List of top-notch VAP performance barriers

\begin{tabular}{|c|c|c|c|c|}
\hline \multirow{2}{*}{ Barriers } & \multicolumn{2}{|c|}{ Agree } & \multicolumn{2}{|c|}{ Disagree } \\
\hline & $\mathbf{F}$ & $\%$ & $\mathbf{F}$ & $\%$ \\
\hline $\begin{array}{l}\text { Having different groups of doctors treating ICU patients complicates the use of } \\
\text { the VAP guidelines. }\end{array}$ & 126 & 63 & 74 & 37 \\
\hline $\begin{array}{l}\text { There are differences in the management of VAP between doctors attending } \\
\text { and ICU workers }\end{array}$ & 98 & 47.5 & 102 & 52.5 \\
\hline $\begin{array}{l}\text { ICU +renal failure patients complicate the decision-making process when } \\
\text { ordering antibiotics. }\end{array}$ & 116 & 58 & 84 & 42 \\
\hline $\begin{array}{l}\text { There is a differencein the control of VAP within the physician service } \\
\text { depending upon who is the attending physician of the VAP patient. }\end{array}$ & 94 & 47 & 106 & 53 \\
\hline
\end{tabular}

\section{Discussion}

Ventilator-related pneumonia (VAP) is one of the hospital-acquired infections most often found in intensive care units and is related to severe morbidity and high care costs. VAP's pathophysiology, epidemiology, diagnosis, and prevention have been researched widely for decades, but no specific preventive strategy has yet emerged.

It revealed, according to the result, that bad knowledge respondents are higher than those who had good knowledge. this result comes in agreements with another study ${ }^{(11)}$ Performed at New Zealand that fond Just $48 \%$ of critical care nurses working in New Zealand have some information about pneumonia prevention associated with ventilator nosocomial. Similar to the literature $^{(12-20)}$, The level of information on VAP among nurses was found to be deficient in the present research. Healthcare teams and academics have put in place and tested various approaches aimed at increasing patient health and reducing inhospitable performance.

Health care-associated infections are the most frequent adverse events that threaten patient safety worldwide. About $5 \%$ to $15 \%$ of patients admitted to intensive care hospitals in developed countries acquire a healthcare-related infection at any time. The risk of developing infection in developing countries is 2 to 20 times higher.Health-associated infections (HAI) pose a danger to the health of patients. CDC offers regional leadership in monitoring, disease investigations, clinical testing and health-associated infection prevention. CDC uses the information gained from these activities to identify infections and establish new approaches to avoid infections associated with the healthcare. CDC and other healthcare agencies 'public health intervention has contributed to changes in clinical practice, medical protocols and the continued development of evidencebased infection control guidelines and advances in prevention. ${ }^{(21-24)}$ However, given the reported findings, there are variations in knowledge of the evidence and the incorporation of evidence-based recommendations into routine nursing. Often, when implementing patient safety or risk management interventions to address healthcare problems, a simple principle must be considered: matching strategies to the source of the problem $^{(25,26)}$. Focusing on all mechanisms known to 
cause VAP allows health care providers to carry out successful risk management measures for patients. ${ }^{(27,28)}$

About the definition of ventilator-related pneumonia, the study found that (\%) of the nurse defined pneumonia and VAP correctly. This result ties well with previous studies wherein the analysis showed that 90 percent of the research sample responded correctly about ventilator definition, and 66.7 percent responded correctly concerning ventilator-related pneumonia (29)Regarding the signs and risk factors of ventilator-associated pneumonia, the study results of the current study were broadly in line with another study that showed the average knowledge of the respondents about signs of ventilator-associated pneumonia was (33.3\%), while the average knowledge of the respondents about risk factors of ventilator-associated pneumonia was $(34.6 \%)^{(30)}$. Additionally, this is similar to what was reported in Boston by a study where average knowledge score was (43.28) percent for signs and symptoms of ventilatorassociated pneumonia ${ }^{(31)}$. Regarding prevention strategies the results of the current study comes in a similar pattern of results was obtained in another study that showed only 31.9 percent of the research sample replied with correct responses about ventilatorassociated pneumonia prevention strategies, while 58.7 percent replied correctly concerning the diagnosis of ventilator-associated pneumonia ${ }^{(32)}$.

Regarding understanding the concept of VAP (50 percent) had strong knowledge, regarding risk factor more than one third (36.7 percent), Regarding knowledge of signs and symptoms of VAP (30 percent) had poor knowledge Concerning knowledge of airway type humidifier (55 percent) had poor knowledge, twothirds ( 65 percent) of nurses changed humidity. And the majority of nurses $(85 \%)$ used open suction, had equal knowledge of endotracheal tube forms $(81 \%){ }^{(33)}$

"The recommended oral route is based on the evidence-based guidelines (EBG's) for the prevention of ventilator-associated pneumonia (VAP). of all the participants, 58(6 9.88\%) responded correctly, and 25 $(30.12 \%)$ responded incorrectly, indicating that nurses know that the oral route is preferred for endotracheal intubation"(34).

The current study indicates the following obstacles to the implementation of VAP-based evidence guidelines: deficiency of resources, no VAP procedure in the unit, and dissatisfaction with the proposed strategy associated with a lack of awareness of the VAP guideline among nurses in Iraq ${ }^{(35)}$.

\section{Conclusion}

Our study indicates that the awareness of nurses about the guidelines for nosocomial pneumonia is not sufficient and highlight the necessity for thorough training and education.

Acknowledgements: The researchers express their gratitude to the 200 nurses serving in teaching Hospitals of Mosul City and especially whose work in ICUs.

Conflict of Interests: No conflict of interest is declared.

Ethical Clearance: Taken from Nineveh Health Directorate- ethical Research committee

Source of Funding: Self

\section{References}

1. Subramanian P, Choy KL, Gobal SV, Mansor $\mathrm{M}, \mathrm{Ng} \mathrm{KH}$. Impact of education on ventilatorassociated pneumonia in the intensive care unit. Singapore Med J. 2013; 54(5):281-4.

2. Llauradó M, Labeau S, Vandijck D, Rello J, Rosa A, Riera A, et al. Southern European intensive care nurses' knowledge of evidence-based guidelines for preventing ventilator-associated pneumonia. Medicina Intensiva (English Edition). 2011; 35(1):6-12.

3. Biancofiore G, Barsotti E, Catalani V, Landi A, Bindi L, Urbani L, et al. Nurses' knowledge and application of evidence-based guidelines for preventing ventilator-associated pneumonia. Minerva anestesiologica. 2007;73(3):129-34.

4. Daud-Gallotti RM, Costa SF, Guimarães T, Padilha KG, Inoue EN, Vasconcelos TN, et al. Nursing workload as a risk factor for healthcare associated infections in ICU: a prospective study. PloS one. 2012;7(12).

5. Yang S-P, Chen Y-Y, Hsu H-S, Wang F-D, Chen L-y, Fung C-P. A risk factor analysis of healthcareassociated fungal infections in an intensive care unit: a retrospective cohort study. BMC infectious diseases. 2013;13(1): 10 .

6. Rodríguez-Acelas AL, de Abreu Almeida M, Engelman B, Cañon-Montañez W. Risk factors for health care-associated infection in 
hospitalized adults: systematic review and metaanalysis. American journal of infection control. 2017;45(12):e149-e56.

7. Petersen PE, Bourgeois D, Ogawa H, EstupinanDay S, Ndiaye C. The global burden of oral diseases and risks to oral health. Bulletin of the World Health Organization. 2005;83:661-9.

8. Sreenivasan VPD, Ganganna A, Rajashekaraiah PB. Awareness among intensive care nurses regarding oral care in critically ill patients. Journal of Indian Society of Periodontology. 2018;22(6):541.

9. Organization WH. Prevention of hospital-acquired infections: a practical guide. Geneva, Switzerland: World Health Organization; 2002.

10. Anderson S, Rigler J, Oberoi V, Christ C, Eggers $\mathrm{P}$, Lempp J, et al. Invasive Staphylococcus aureus Infections Associated with Pain Injections and Reuse of Single-Dose Vials- Arizona and Delaware, 2012. Morbidity and Mortality Weekly Report. 2012;61(27).

11. Soh KL, Wilson J, Koziol-McLain J, Soh KG. Critical care arenurses' knowledge in preventing nosocomial pneumonia. Australian Journal of Advanced Nursing, The. 2007;24(3):19.

12. Yamagata A, Ito A, Nakanishi $\mathrm{Y}$, Ishida $\mathrm{T}$. Prognostic factors in nursing and healthcareassociated pneumonia. Journal of Infection and Chemotherapy. 2020.

13. Tanguay A, LeMay S, Reeves I, Gosselin É, StCyr-Tribble D. Factors influencing oral care in intubated intensive care patients. Nursing in Critical Care. 2020;25(1):53-60.

14. Zed SAFA, Mohammed AA. Impact of nursing guidelines on nurses' knowledge and performance regarding to prevention of ventilator associated pneumonia in neonates. Journal of Nursing Education and Practice. 2019;9(10).

15. Saensom D, Merchant A, Wara-Aswapati N, Ruaisungnoen W, Pitiphat W. Oral health and ventilator-associated pneumonia among critically ill patients: a prospective study. Oral diseases. 2016;22(7):709-14.

16. Atashi V, Yousefi H, Mahjobipoor H, Yazdannik A. The barriers to the prevention of ventilatorassociated pneumonia from the perspective of critical care nurses: A qualitative descriptive study. Journal of clinical nursing. 2018;27(5-6):e1161-e70.

17. Wami GA, Mengistu D, Gudisa GG. Knowledge,
Practice and Associated Factors of Adult Intensive Care Nurses' on Prevention of Ventilator Associated Pneumonia in Addis Ababa Public Hospitals, Addis Ababa, Ethiopia. Dermatology. 2018;1(1):15-21.

18. Mohammed MAA. Assessment of nurses knowledge and Performance regarding prevention of Ventilator associated pneumonia in Intensive Care Unit in Omdurman military hospital during the period of study August 2017: Mariam Mohammed Elnagieb; 2017.

19. Yazdannik A, Atashi V, Ghafari S. Performance of ICU nurses in providing respiratory care. Iranian journal of nursing and midwifery research. 2018;23(3):178.

20. Ab Manap N. Critical Care Nurses Knowledge in Prevention of Ventilator-Associated Pneumonia. ILKKM Journal of Medical and Health Sciences. 2019;1(1):25-30.

21. Lerma FÁ, García MS, Lorente L, Gordo F, Añón $\mathrm{J}$, Álvarez J, et al. Guidelines for the prevention of ventilator-associated pneumonia and their implementation. The Spanish "Zero-VAP" bundle. Medicina intensiva. 2014;38(4):226-36.

22. Mehta Y, Gupta A, Todi S, Myatra S, Samaddar D, Patil V, et al. Guidelines for prevention of hospital acquired infections. Indian journal of critical care medicine: peer-reviewed, official publication of Indian Society of Critical Care Medicine. 2014;18(3):149.

23. Coffin SE, Klompas M, Classen D, Arias KM, Podgorny K, Anderson DJ, et al. Strategies to prevent ventilator-associated pneumonia in acute care hospitals. Infection Control \& Hospital Epidemiology. 2008;29(S1):S31-S40.

24. Klompas M, Branson R, Eichenwald EC, Greene LR, Howell MD, Lee G, et al. Strategies to prevent ventilator-associated pneumonia in acute care hospitals: 2014 update. Infection Control \& Hospital Epidemiology. 2014;35(S2):S133-S54.

25. DiCenso A, Guyatt G, Ciliska D. Evidence-Based Nursing-E-Book: A Guide to Clinical Practice: Elsevier Health Sciences; 2014.

26. Dang D, Dearholt SL. Johns Hopkins nursing evidence-based practice: Model and guidelines: Sigma Theta Tau; 2017.

27. Martinez EA, Varughese AM, Buck DW, Heitmiller ES. Quality Improvement and Patient Safety. Miller R, Eriksson L, Fleisher L, Wiener-Kronish 
J, Cohen N, Young W Miller's Anesthesia 8th ed Netherland: Elsevier. 2019:87-05.

28. Corsi-Vasquez G, Ostrosky-Zeichner L. Infection Prevention in Critical Care Settings. Oncologic Critical Care. 2020:1275-86.

29. Wood GC, Boucher BA, Croce MA, Hanes SD, Herring VL, Fabian TC. Aerosolized ceftazidime for prevention of ventilator-associated pneumonia and drug effects on the proinflammatory response in critically ill trauma patients. Pharmacotherapy: The Journal of Human Pharmacology and Drug Therapy. 2002;22(8):972-82.

30. Ali NS. Critical Care Nurses' knowledge and compliance with ventilator associated pneumonia bundle at Cairo university hospitals. Crit Care. 2013;4(15):66-78.

31. Idress WMO. Nurse's Knowledge and Practice Regarding Nursing Care of Patients with Ventilator Associated Pneumonia at Ahmed Gasim Hospital, Khartoum State, Sudan (2017): University of Gezira; 2017.

32. Saito N, Yagi T, Hara Y, Matsumoto H, Mashiko
K. Simple predictive scoring system for ventilatorassociated pneumonia in trauma patients. Critical Care. 2011; 15(1): P453.

33. Ahmed GE, Abosamra OM. Knowledge of Pediatric Critical Care Nurses Regarding EvidenceBasedGuidelines for Prevention of Ventilator Associated Pneumonia (VAP). Journal of Education and Practice. 2015; 6(9):94-101.

34. Nair GB, Niederman MS, editors. Using ventilatorassociated pneumonia rates as a health care quality indicator: a contentious concept. Seminars in respiratory and critical care medicine; 2017: Thieme Medical Publishers.

35. Jahansefat L, Vardanjani MM, Bigdelian $\mathrm{H}$, Massoumi G, Khalili A, Mardani D. Exploration of knowledge of, adherence to, attitude and barriers toward evidence-based guidelines (EBGs) for prevention of ventilator-associated pneumonia (VAP) in healthcare workers of pediatric cardiac intensive care units (PCICUs): A Quali-Quantitative survey. International Journal of Medical Research \& Health Sciences. 2016; 5(9):67-73. 